\title{
Soft-Chemical Synthesis of Vanadium Oxide Nanostructures Using 3, 3', 3”-Nitrilotripropionic Acid (NTP) as a Carrier
}

\author{
V. S. Reddy Channu ${ }^{1 *}$, Rudolf Holze ${ }^{1}$, B. Rambabu ${ }^{2}$ \\ ${ }^{1}$ Institut für Chemie, AG Elektrochemie, Technische Universität Chemnitz, Chemnitz, Germany; ${ }^{2}$ Solid State Ionics and Surface \\ Sciences Lab, Department of Physics, Southern University and A \& M College, Baton Rouge, USA. \\ Email: chinares02@gmail.com
}

Received March 10 ${ }^{\text {th }}$, 2011; revised May 12 ${ }^{\text {th }}$ 2011; accepted June $10^{\text {th }}, 2011$.

\begin{abstract}
Vanadium oxide nanostructures were synthesized using NTP as a carrier through soft-chemical method. The influence of calcination temperature on the phase and morphology of obtained pristine product were characterized using $X$-ray diffraction (XRD), thermal gravimetric analysis (TGA) and scanning electron microscopy (SEM). Cyclic voltammogram studies were conducted to examine the electrochemical performance of cathodes made of vanadium oxide nanostructures. $X$-ray diffraction results show that, the particle size of the nanomaterials is increases with the increasing of calcination temperature.
\end{abstract}

Keywords: Nanomaterials, Soft-Chemical Method, Morphology, Cyclic Voltammogram

\section{Introduction}

Divanadium pentoxide $\left(\mathrm{V}_{2} \mathrm{O}_{5}\right)$, the most stable form in the V-O system, has been at the front position of applied research due to its unique physio-chemical properties. The layered crystal structure of vanadium oxide nanostructures are currently drawn attention for the application of super capacitors and chemical sensors [1,2], electrical and optical properties, has led to wide potential applications including rechargeable lithium batteries [3] and optical data storage media [4,5]. Vanadium pentoxide exhibits a number of polymorphs, including $\alpha-\mathrm{V}_{2} \mathrm{O}_{5}$ (orthorhombic) [6], $\beta-\mathrm{V}_{2} \mathrm{O}_{5}$ (monoclinic or tetragonal) and $\gamma-\mathrm{V}_{2} \mathrm{O}_{5}$ (orthorhombic) [7]. The $\alpha-\mathrm{V}_{2} \mathrm{O}_{5}$ phase is the most stable phase and the other two phases can be converted from the $\alpha-\mathrm{V}_{2} \mathrm{O}_{5}$ phase under high temperature and high pressure [8]. Vanadium oxide based catalysts are widely used in a variety of chemical reactions like reduction of $\mathrm{NO}_{\mathrm{x}}$ or partial oxidation of alkanes [9].

Synthesis of a wide range of nanostructures predominantly, high order nanomaterials with well defined geometries such as nanorods, nanobelts, nanotubes and nanowires have attracted fabulous interest due to their novel chemical and physical properties and their prospective applications in fabricating electronic, magnetic, optical, electrochemical devices [10-16].
There are several methods available for the synthesis of vanadium oxides nanostructures [17]. To develop a new method with desirable practical attributes, such as avoiding extreme pressure conditions, simplicity and catalyst-free [18] are needed. In this work, we have synthesized vanadium pentoxide nanostructures by soft-chemical method under ambient conditions using 3, 3', 3"Nitrilotripropionic Acid (NTP) as a carrier.

\section{Experimental}

3, 3', 3"-Nitrilotripropionic Acid (NTP) was synthesized using green chemical method [19]. 1 gm of $\mathrm{V}_{2} \mathrm{O}_{5}$ powder was slowly dissolved in $100 \mathrm{~mL}$ diluted hydrogen peroxide solution. A transparent yellow solution was formed after completely dissolved $\mathrm{V}_{2} \mathrm{O}_{5} .2 .57$ gm of NTP was dissolved in $75 \mathrm{~mL}$ of distilled water at $80^{\circ} \mathrm{C}$ this solution was added into the above transparent yellow solution. The mixed solution transferred into $500 \mathrm{~mL}$ round-bottom flask and kept at $80^{\circ} \mathrm{C}$ on the hot plate for $1 \mathrm{~h}$ to evaporate the solution. After reaction at $80^{\circ} \mathrm{C}$, the transparent yellow color turned into a green color solution which indicates reduction of $\mathrm{V}^{+5}$. A bulky green gel of high viscosity was obtained after slowly vaporizing the solution at $80^{\circ} \mathrm{C}$ by rotary evaporation. The obtained green gel heat treated at $200^{\circ} \mathrm{C}$ for $4 \mathrm{~h}$ in vacuum oven. 


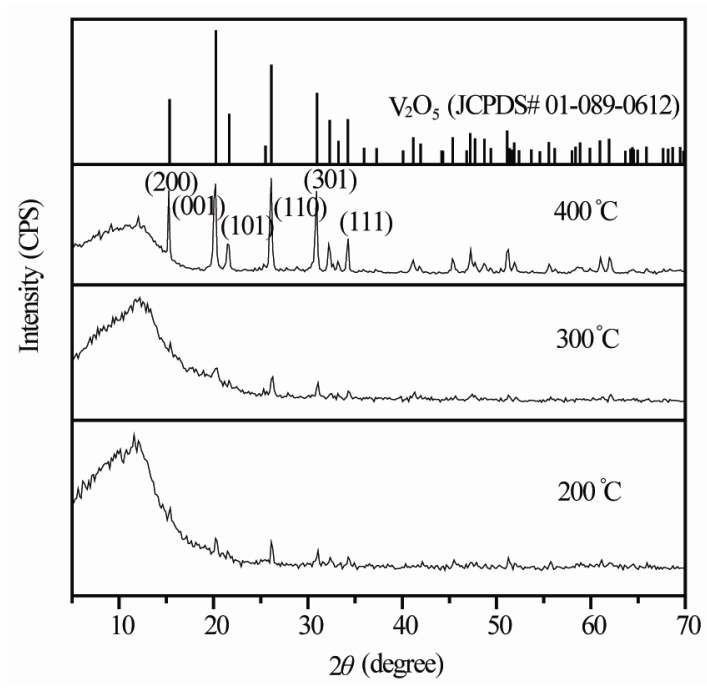

Figure 1. XRD patterns of vanadium oxide nanostructures dried at different temperatures.

The final product was then ground and calcinated at $300^{\circ} \mathrm{C}$ and $400^{\circ} \mathrm{C}$ for $4 \mathrm{~h}$ in an oven.

Crystallographic information of the samples was obtained using a X-ray powder diffractometer (D8 Advanced Brucker ) equipped with graphite monochromatized $\mathrm{Cu} \mathrm{K} \alpha$ radiation $(\lambda=1.54187 \AA$ ). Diffraction data was collected over the $2 \theta$ range of $5^{\circ}$ to $70^{\circ}$. The morphologies of the resulting products were characterized using a scanning electron microscope (SEM, JEOL JSM 6390). For the TGA measurements a TA 600, operating in dynamic mode (heating rate $=10^{\circ} \mathrm{C} / \mathrm{min}$ ), was employed. The electrochemical properties of the nanomaterials were investigated with a three-electrode cell with a platinum counter electrode and a silver (Ag) wire as a reference electrode. The working electrode, prepared by mixing $80 \mathrm{wt} \%$ of active material, $15 \mathrm{wt} \%$ of acetylene black and $5 \mathrm{wt} \%$ of polytetrafluoroethylene (PTFE), was then coated on a $1.0 \mathrm{~cm}^{2}$ ITO glass. A solution of 1 M lithium perchlorate (99.99\%, Aldrich) in propylene carbonate (99.7\%, Aldrich) was used as the electrolyte after purification by recrystallization and distillation, respecttively. Cyclic voltammetric (CV) measurements were carried out between the potential limits of $-1.0 \mathrm{~V}$ and $+1.0 \mathrm{~V}$ versus a Ag wire with a potentiostat/galvanostat (PRE 273). The CV curves were recorded at a scan rate of $5 \mathrm{mV} / \mathrm{s}$.

\section{Results and Discussion}

Figure 1 shows XRD patterns of vanadium oxide nanostructures at different temperatures. Though as obtained product dried at $200^{\circ} \mathrm{C}$ and $300^{\circ} \mathrm{C}$ showed less intense diffraction peaks, all the diffraction patterns indicate $\mathrm{V}_{2} \mathrm{O}_{5}$ and no peaks related to the carrier (NTP) were ob- served. The precursor heated at $400^{\circ} \mathrm{C}$ showed the development intense diffraction peaks corresponding to the orthorhombic structured $\mathrm{V}_{2} \mathrm{O}_{5}$ with lattice parameters $\mathrm{a}=$ $11.48 \AA, \mathrm{b}=4.36 \AA$ and $\mathrm{c}=3.55 \AA$ [JCPDS\#01-0890612]. Note that the broad hump at $2 \theta=10^{\circ}-15^{\circ}$ in all the samples reveals the experimental error in the sample preparation for recording XRD spectrum.

Figure 2 shows the thermo gravimetric analysis (TGA) of as obtained product at $70^{\circ} \mathrm{C}$. Two types of water are contained within vanadium oxide, absorbed and chemically bound water. Absorbed water, weakly associated with $\mathrm{V}_{2} \mathrm{O}_{5}$ layers, is located on top the layers while chemically bound water is located inside the layers. During thermal treatment of the material, the absorbed and chemically bound water molecules become mobile. The weakly bound absorbed water becomes energized and mobile at lower temperature than strongly held chemically bound water. The interlayer distance does not change much when only bound water (reversibly absorbed or hydrogen-bonded water) is removed. These parameters will alter considerably only when tightly bound (chemically bonded) water is removed and the material is on the verge of crystallization.

The weight loss in the sample happens in three steps due to the release of absorbed and chemically bound intercalated water molecules and decomposition of carrier. The first weight loss is $0.048 \mathrm{mg}$ due to the loss of absorbed and weakly bound water in the temperature range $50^{\circ} \mathrm{C}-165^{\circ} \mathrm{C}$. The second and third weight losses are 0.092 and $0.419 \mathrm{mg}$, respectively, in the temperature range $165^{\circ} \mathrm{C}-510^{\circ} \mathrm{C}$ due to the release of more strongly bonded water, departure of chemically bonded water and decomposition of carrier (NTP). The curve depicts steep slope between $300^{\circ} \mathrm{C}$ to $500^{\circ} \mathrm{C}$. The steep slope indicates a rapid loss of mass in this temperature range.

Figure 3 shows the scanning electron microscopy (SEM) images of vanadium oxide nanostructures at different temperatures. SEM images of as obtained pro-

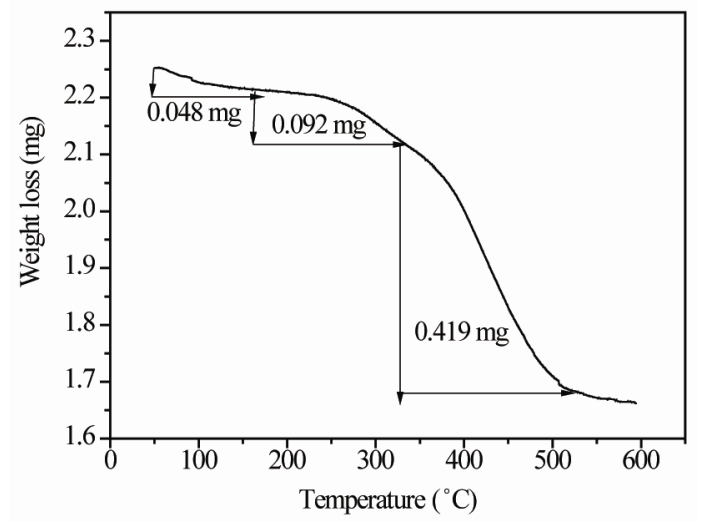

Figure 2. TGA curve of green gel at $70^{\circ} \mathrm{C}$. 


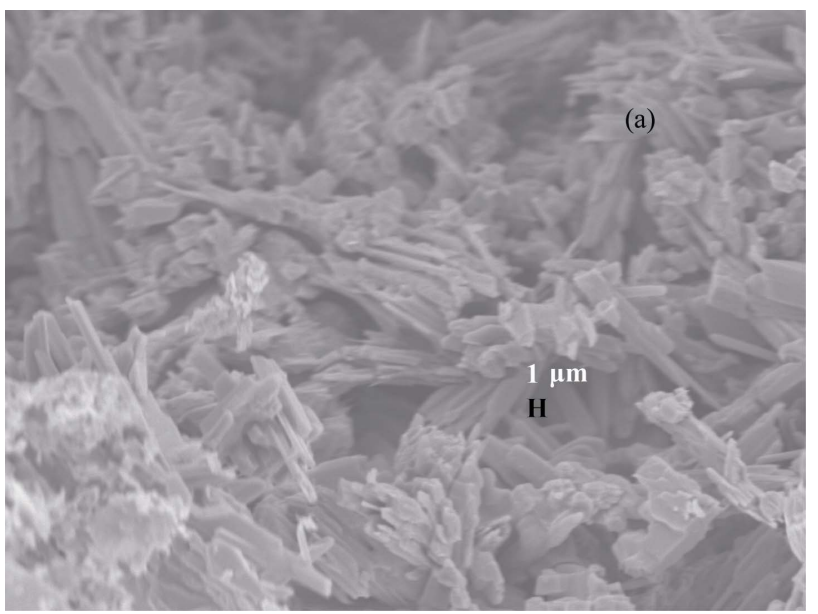

(a)

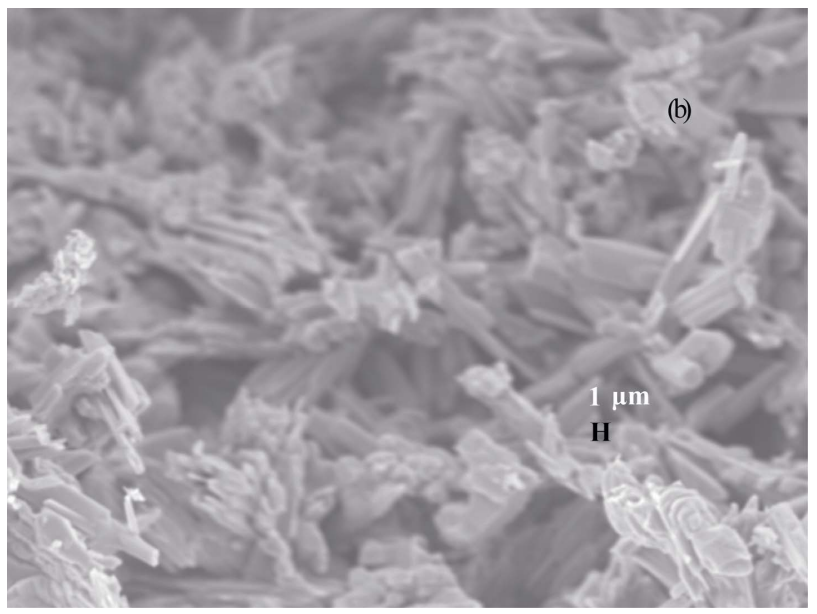

(b)

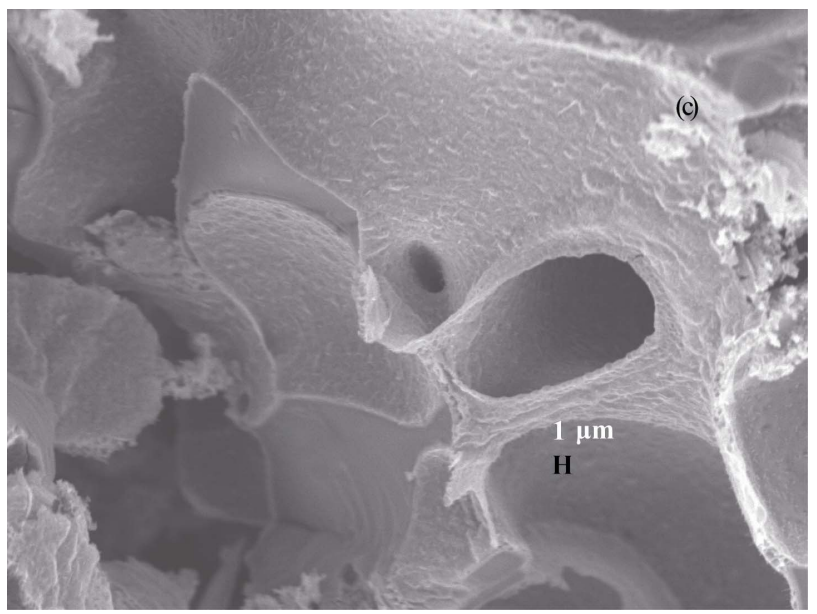

(c)

Figure 3. SEM photographs of vanadium oxide nanostructures at (a) $200^{\circ} \mathrm{C}$, (b) $300^{\circ} \mathrm{C}$ and (c) $400^{\circ} \mathrm{C}$.

duct dried at $200^{\circ} \mathrm{C}$ and $300^{\circ} \mathrm{C}$ (Figures 3(a) and (b)) reveal that the belts are tens of micrometers long, 50 $100 \mathrm{~nm}$ wide and 5 - $10 \mathrm{~nm}$ thick. The SEM image of as obtained product dried at $400^{\circ} \mathrm{C}$ (Figure 3(c)) shows the porous structure with bigger pore diameter, and this might be due to the complete decomposition of the carrier (NTP).

Cyclic voltammograms of vanadium oxide nanostructures dried at $200^{\circ} \mathrm{C}$ and $300^{\circ} \mathrm{C}$ are shown in Figures 4 and 5. The capacitance of the working electrode was calculated using $\mathrm{C}=\mathrm{i} / \mathrm{Sm}$ where $\mathrm{i}$ is the average current of the anodic and cathodic curves, $\mathrm{S}$ is the scan rate; $\mathrm{m}$ is the active mass of the working electrode. The calculated capacity is $10.54 \mathrm{~F} / \mathrm{g}$ for working electrode made of vanadium oxide nanostructures dried at $200^{\circ} \mathrm{C}$ and 14.78 $\mathrm{F} / \mathrm{g}$ for working electrode made of vanadium oxide nano-

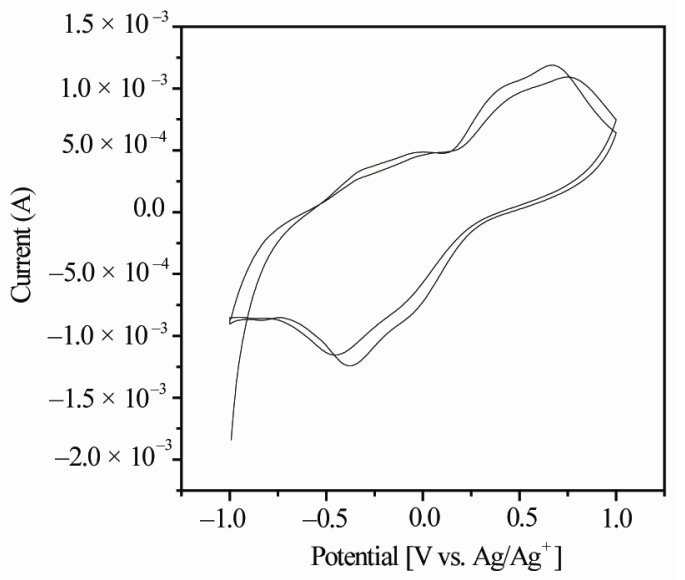

Figure 4. Cyclic voltammagram of vanadium oxide nanostructures dried at $200^{\circ} \mathrm{C}$ in non-aqueous electrolyte $(1 \mathrm{M}$ $\mathrm{LiClO}_{4}$ dissolved in propylene car-bonate) with scan rate of $5 \mathrm{mV} / \mathrm{s}$.

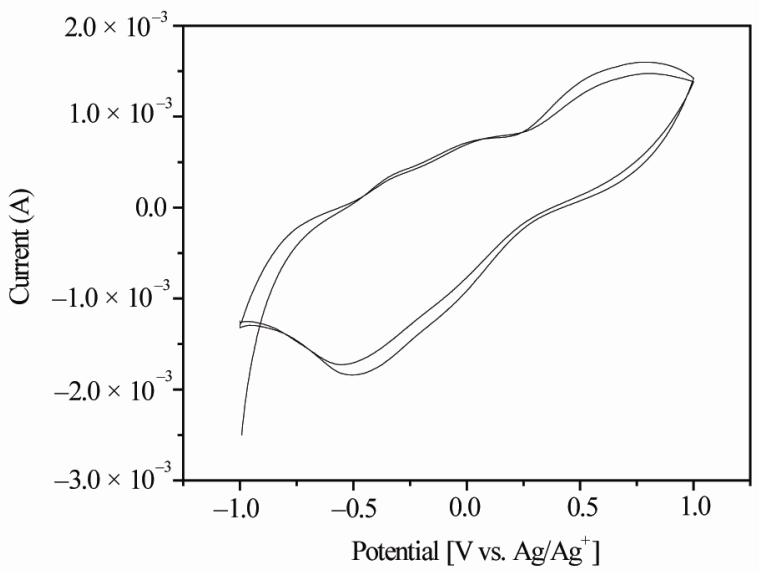

Figure 5. Cyclic voltammagram of vanadium oxide nanostructures dried at $300^{\circ} \mathrm{C}$ in non-aqueous electrolyte $(1 \mathrm{M}$ $\mathrm{LiClO}_{4}$ dissolved in propylene car-bonate) with scan rate of $5 \mathrm{mV} / \mathrm{s}$. 
structures dried at $300^{\circ} \mathrm{C}$. The working electrode made of vanadium oxide dried at $200^{\circ} \mathrm{C}$ exhibits broad anodic and cathodic peaks at $+0.67 \mathrm{~V}$ and $-0.37 \mathrm{~V}$ (Figure 4), respectively. The working electrode made of vanadium oxide dried at $300^{\circ} \mathrm{C}$ shows broad anodic and cathodic peaks at $+0.7 \mathrm{~V}$ and $-0.5 \mathrm{~V}$ (Figure 5), respectively. The cathodic reduction peak refers to the electrical energy stored in the form of chemical potential $\left(\mathrm{Li}^{+}\right.$intercalation) and the anodic oxidation peaks correspond to the chemical energy released in the form of electricity $\left(\mathrm{Li}^{+}\right.$ de-intercalation).

\section{Conclusions}

Vanadium oxide nanostructures are successfully synthesized in bulk quantity by soft-chemical method using 3 , 3', 3"-Nitrilotripropionic Acid (NTP) as a carrier. Thermogravmetric results revels weight loss in the sample happens in three steps due to the release of absorbed and chemically bound intercalated water molecules and decomposition of carrier. The crystallinty of the vanadium oxide nanostructures improves with increase of dried temperature as obtained product. The capacity of the working electrode is increases with increase of dried temperature of as obtained product.

\section{Acknowledgements}

One of the authors (VS Reddy Channu) thank the Alexander von Humboldt Foundation for a fellow-ship. This work is partially supported by U.S-DOD-ARO-HBCU/ MI.

\section{REFERENCES}

[1] R. N. Reddy and R. G. Reddy, "Porous Structured Vanadium Oxide Electrode Material for Electrochemical Capacitors," Journal of Power Sources, Vol. 156, No. 2, 2006, pp. 700-704. doi:10.1016/j.jpowsour.2005.05.071

[2] J. Liu, X. Wang, Q. Peng and Y. Li, "Vanadium Pentoxide Nanobelts: Highly Selective and Stable Ethanol Sensor Materials,” Advanced Materials, Vol. 17, No. 6, 2005, pp. 764-767. doi:10.1002/adma.200400993

[3] C. Lampe-Onnerud, J. O. Thomas, M. Hardgrave and S. Yde-Anderson, "The Performance of Single-Phase $\mathrm{V}_{6} \mathrm{O}_{13}$ in the Lithium/Polymer Electrolyte Battery," Journal of Electrochemical Society, Vol. 142, No. 11, 1995, pp. 3648-3651. doi:10.1002/adma.200400993

[4] I. Balberb and S. Trokman, "High-Contrast Optical Storage in $\mathrm{VO}_{2}$ Films," Journal of Applied Physics, Vol. 46, No. 5, 1975, pp. 2111-2119. doi:10.1063/1.321849

[5] K. C. Cam and A. K. Cheetham, "Thermochromic $\mathrm{VO}_{2}$ Nanorods and Other Vanadium Oxides Nanostructures," Materials Research Bulletin, Vol. 41, No. 5, 2006, pp. 1015-1021. doi:10.1016/j.materresbull.2006.03.024
[6] P. Singh and D. Kaura, "Influence of Film Thickness on Texture and Electrical and Optical Properties of Room Temperature Deposited Nanocrystalline $\mathrm{V}_{2} \mathrm{O}_{5}$ Thin Films,” Journal of Applied Physics, Vol. 103, No. 4, 2008, pp. 043507-043507-9. doi:10.1063/1.2844438

[7] Q. Su, W. Lan, Y. Y. Wang and X. Q. Liu, "Structural Characterization of $\beta-\mathrm{V}_{2} \mathrm{O}_{5}$ Films Prepared by DC Reactive Magnetron Sputtering,” Applied Surface Science, Vol. 255, 2009, pp. 4177-4179. doi:10.1016/j.apsusc.2008.11.002

[8] P. Balog, D. Orosel, Z. Cancarevic, C. Schön and M. Jansen, " $\mathrm{V}_{2} \mathrm{O}_{5}$ Phase Diagram Revisited at High Pressures and High Temperatures,” Journal of Alloys \& Compounds, Vol. 429, No. 1-2, 2007, pp. 87-98. doi:10.1016/j.jallcom.2006.04.042

[9] G. Ertl, H. Knozinger and J. Weitkamp (Eds.), "Hand Book of Heterogenous Catalysis," Vol. 4, Wiley-VCH, Weinhem, 1997.

[10] Y. Yang, L. Xiao, Y. Zhao and F. Wang, "Hydrothermal Synthesis and Electrochemical Characterization of a$\mathrm{MnO}_{2}$ Nanorods as Cathode Material for Lithium Batteries," International Journal of Electrochemical Science, Vol. 3, No. 1, 2008, pp. 67-74.

[11] L. Q. Mai, B. Hu, Y. Qi, Y. Dai and W. Chen, "Improved Cycling Performance of Directly Lithiated $\mathrm{MoO}_{3}$ Nanobelts," International Journal of Electrochemical Science, Vol. 3, No. 2, 2008, pp. 216-222.

[12] M. E. G. Lyons, "Transport and Kinetics at Carbon Nanotube-Redox Enzyme Composite Modified Electrode Biosensors Part 2. Redox Enzyme Dispersed in Nanotube Mesh of Finite Thickness," International Journal of Electrochemical Science, Vol. 4, No. 9, 2009, pp. 11961236.

[13] C. Kong, Z. A. Hu, H. X. Zhao, Y. Y. Yang, X. L. Shang, L. J. Ren and Y. P. Wang, "Preparation of Ag Nanowire Array Electrode by Transplantation and Its Electrochemical Activities," International Journal of Electrochemical Science, Vol. 2, No. 2, 2007, pp. 133-140.

[14] K. Takahashi, S. J. Limmer, Y. Wang and G. Z. Cao, "Synthesis and Electrochemical Properties of SingleCrystal $\mathrm{V}_{2} \mathrm{O}_{5}$ Nanorod Arrays by Template-Based Electrodeposition," Journal of Physical Chemistry B, Vol. 109, No. 8, 2004, pp. 9795-9800. doi:10.1021/jp0491820

[15] S. Nordlinder, K. Edstrom and T. Gustafsson, “The Performance of Vanadium Oxide Nanorolls as Cathode Material in a Rechargeable Lithium Battery," Electrochemical and Solid-State Letters, Vol. 4, No. 8, 2001, pp. A129-A131. doi:10.1149/1.1382888

[16] P. Liu, J. G. Zhang, C. E. Tracy and J. A. Turner, "Electrochemical Deposition of Vanadium Oxide in the Presence of Surfactants A Novel Approach toward High-Rate Lithium Battery Cathodes,” Electrochemical and SolidState Letters, Vol. 3, No. 4, 2000, pp.163-166. doi:10.1149/1.1390990

[17] Y. Wang and G. Cao, "Synthesis and Enhanced Intercalation Properties of Nanostructured Vanadium Oxides," 
Chemical Materials, Vol. 18, No. 12, 2006, pp. 27872804. doi: $10.1021 / \mathrm{cm} 052765 \mathrm{~h}$

[18] Z. Zheng, B. Yan, Y. You, J. Zhang, Z. X. Shen, C.-T. Lim and T. Yu, "Potassium Tungsten Bronze Nanowires: Polarized Micro-Raman Scattering of Individual Nanowires and Electron Field Emission from Nanowire Films,” Advanced Materials, Vol. 20, 2008, pp. 352-356. doi:10.1002/adma.200701514

[19] E. H. Walker Jr., A. W. Apblett, R. Walker and A. Zachary, "The Novel Synthesis of $\mathrm{La}_{0.8} \mathrm{Sr}_{0.2} \mathrm{MnO}_{3}$ Using the Michael-Addition Directed Hydrogelation of Acrylates for Materials Synthesis (MADHAMS) Method," Chemi- cal Materials, Vol. 16, No. 25, 2004, pp. 5336-5343. doi:10.1021/cm0489385

[20] V. S. R. Channu, R. Holze, B. Rambabu, Q. L. Williams, R. R. Kalluru and W. Chen, "Reduction of $\mathrm{V}^{4+}$ from $\mathrm{V}^{5+}$ Using Polymer as a Surfactant for Electrochemical Applications," International Journal of Electrochemical Science, Vol. 5, 2010, pp. 605-614.

[21] M. Jayalakshmi and K. Balasubramanian, "Simple Capacitors to Supercapacitors-An Overview," International Journal of Electrochemical Science, Vol. 3, 2008, pp. 1196-1217. 